\title{
Pronunciation and Independent Work: Embedding Pronunciation into Academic English Skill Classes
}

\author{
Nonna Danchenko \\ (International Pacific College (IPC), New Zealand) \\ doi:10.7575/aiac.alls.v.2n.2p.171
}

\begin{abstract}
This paper describes an experiment carried out at International Pacific College (IPC) as part of an EAP (English for Academic Purposes) paper taught in year one of the BA programme. The trial was aimed at instilling students with the motivation to self-monitor their pronunciation, attempting to raise it to an internationally acceptable level of intelligibility. In this experiment, the students were encouraged to take responsibility for progress and competency within both reading and pronunciation. A fundamental part of the process was embedding pronunciation into as many academic skills as possible, including reading, listening, and note taking.
\end{abstract}

\section{Introduction}

Pronunciation is said to be an area of language central to effective and successful communication for learners. In spite of this, ESOL conference programmes contain considerably fewer presentations dealing with issues of pronunciation than with any other aspect of language teaching. Similarly, after scanning professional applied linguistics journals for articles on pronunciation, one would have to concede that such articles are very few and far between. It comes as no surprise, then, that pronunciation is often referred to as the Cinderella of English language teaching (Kelly, 1969, as cited in Celce-Murcia, Brinton, \& Goodwin, 1996, p. 2).

The relative reluctance of teachers to share their experience of teaching English pronunciation might be explained by the fact that ESL teaching is dominated by other concerns. EAP papers, for example, are focused primarily on facilitating students' learning of academic English skills, such as essay writing, note taking, referencing, reading, vocabulary acquisition, etc. Stifled by multiple academic concerns, teachers are often forced to abandon efforts with pronunciation, or at least put it on the back burner. As a result, students receive 
little encouragement to change their pronunciation, an area which is not universally considered to be 'academic'.

This is a paradoxical situation. On the one hand, the premise that limited pronunciation skills can undermine learners' self confidence, restrict social interactions, and negatively influence estimations of a speaker's credibility and abilities is widely accepted (Morley, 1998). On the other, many researchers refer to the marginalisation of pronunciation within applied linguistics (Derwing \& Munro, 2005; Celce-Murcia, Brinton, \& Goodwin, 1996, Wajnryb, 2004, Levis, 2007). As a result, a key area for student success in ESL is not addressed. Reconciliation of this unfortunate paradox is what I was trying to achieve, in a commitment to addressing my students' overall communicative needs comprehensively and effectively.

There is little disagreement over the need for ESL students to lift their oral performance. It is self evident that students who choose to pursue their education in an English-speaking country put a high value on communication, both written and oral, and with both native and non-native speakers (NS and NNS) of English. Apart from using English for their social, outof-class needs, students have to express their opinions and develop arguments in ongoing class and group discussions, exchanging ideas with the teacher and with peers. Under the circumstances, most teachers are aware of their students' individual pronunciation errors and of the benefit of developing good pronunciation. If, however, pronunciation is not part of the classroom routine, then it is likely that the teacher either doesn't know how to deal with pronunciation in class or else hopes that the greater English-speaking environment will fix it.

In reality, we have to take into account that the majority of students come to an Englishspeaking country at the age of 18 or over. To rely on a natural, unconscious self-correction mechanism is naive. Of course some students with an ear for languages will improve their own pronunciation, but the majority need external feedback on what makes their pronunciation difficult to understand and how to make specific changes. M. Pennington sums it up with conviction:

Whether you believe pronunciation should be taught explicitly or allowed to be developed without explicit instruction, as an autonomous course or as a skill integrated into other language skill areas, for every language teacher, the question of the place of pronunciation in the English curriculum needs to receive an answer of some kind. (Pennington, 1997, p. 218) 
Pronunciation has assumed particular prominence today, when there are more learners of English around the world than there are native speakers of it, and when issues of mutual intelligibility are of major concern (Jenkins, 2000). With the spread of globalisation and a global demand for communication, the goal of NNS students attaining near-native pronunciation has been superceded. New objectives in pronunciation have thus shifted away from a generally-unattainable native-speaker standard to a broader, more accommodating and inclusive notion of intelligibility. This paradigm shift in pronunciation standards and an evergrowing demand for English-language learning has effected another important change, i.e. the shift of responsibility for pronunciation accuracy from the teacher to the learner.

\section{Learning versus teaching}

At present, the teaching of pronunciation involves implementing a programme which is workable (on the part of both teachers and learners) and which responds to students' immediate needs. Research on classroom-based approaches to pronunciation has not yet established the best way to incorporate it into an ESOL curriculum (Levis, 2005). If we assume that there is, in fact, more than one way to do this, then it is clear that 'pronunciation learning' is preferable to 'pronunciation teaching' (Brown, 1991, p. 1). The shift in balance between the two points of view provides additional opportunities for both teachers and learners to develop their own approaches to pronunciation instruction, whether dramatic, such as a new pronunciation curriculum (Morley, 1994), or part of a mix, integrating pronunciation with other skills of language acquisition like, for instance, EAP (Murphy \& Kandil, 2004). In either case, the move to learners assuming control is the obvious result of teachers deciding to 'empower' students to deal with their own individual pronunciation problems. Therefore, 'empowerment' should be a dimension of instruction in pronunciation...' (Dickerson, 1994, p.19). The teacher's role is confined to facilitating this process by providing expert advice and encouragement until an acceptable level of intelligibility is achieved.

\section{Intelligibility: Easy to recognise, hard to define}

Assessment of intelligibility is a minefield. It requires us to consider whether there is consensus on what 'an acceptable level of intelligibility' represents in the context of English as an International Language (EIL) or English as a Lingua Franca (ELF). As Jenkins (2000, p.70) states 'there is as yet no broad agreement on a definition of the term 'intelligibility': it can mean different things to different people". 
To add to the confusion, the concept of intelligibility is probably easier to assess in real life than to define on paper. That may be why many scholars write about the importance of intelligibility for language learners but rarely give a definition, often taking our understanding of the term for granted (Action, 1984, p. 73; Brown, 1991, p.44; Dalton \& Seidlhofer, 1994, p. 9; Kenworthy, 1987, p. 3). Traditionally, the term 'intelligibility' was used to indicate an L2 speaker's reasonably-close adherence to RP pronunciation, thus making it comparatively easy for a native speaker to understand foreign speech (Gimson, 1989).

The word 'intelligibility' has undergone a process of redefinition, in view of EIL and its dominance worldwide. Until recently in linguistic literature, there was a prevalence of definitions that treated intelligibility from the perspective of a native speaker (Bamgbose, 1998, p. 10). Nowadays, the emphasis is on international intelligibility. Thus, the term 'intelligibility' currently includes an active role for non-native speakers (NNS), suggesting mutual intelligibility as a common goal for NNS of various nationalities.

Because the term 'intelligibility' is central to this paper, we need to look for an acceptable definition. In linguistic literature, 'intelligibility' can refer to any aspect of the language, including appropriate grammar use, the right choice of words, coherent discourse, etc. Conscious of the difficulty this creates, Smith and Nelson advocate for a more restrictive use of it. They present language accuracy as a three-tiered hierarchy: intelligibility (word/utterance recognition), comprehensibility (the meaning of a word or an utterance recognised), and interpretability (the meaning behind the word or utterance recognised). (Smith \& Nelson, 1985, pp. 333-334). For the most comprehensive terminology summary one can read Cruz (2007).

In this experiment the oral perception of language is paramount. In this regard, Underhill emphasises the reciprocal nature of intelligibility and writes about 'comfortable intelligibility", which means that learners "can be understood comfortably, without undue effort by the listener, and that they can understand comfortably the speech of native and other speakers without undue effort on their own part" (Underhill, 1994, p. 171). Similarly, Harmer suggests that intelligibility implies, "students should be able to use pronunciation which is good enough for them to be always understood" (Harmer, 2001, p. 184). 
As we see, none of the above definitions of intelligibility contain distinct phonemic parameters. Dauer cautions that, "although everyone states that the goal of pronunciation instruction is intelligibility, it is difficult to define or to measure" (Dauer, 2005, p. 548). For this reason, intelligibility generally presupposes that a speaker is comfortably understood by a variety of English-speaking listeners, whether of native and non-native descent. The 'paradigm shift' caused by the increasing use of English as an International Language made researchers take a new look at intelligibility (Pickering, 2006). While a range of accents is acceptable, all accents have to correspond to a certain international standard, or 'phonological core', as Jennifer Jenkins calls it (Jenkins, 2000, p. 99). It is very hard to achieve an international standard if pronunciation awareness and pronunciation teaching are eliminated from the classroom.

For the purposes of this research, I have chosen to use the term 'intelligibility' in its narrow sense, focusing on phonological intelligibility, which itself is 'extremely difficult to isolate and pin down' (Jenkins, 2000, p. 2). Intelligibility is therefore understood to be individual speech or pronunciation that presents no difficulty for decoding and is easily comprehensible in an international class environment. Thus, phonological intelligibility is our prime concern. The focus of this article is on integrating pronunciation into an EAP paper as experimentally taught at International Pacific College in New Zealand. It grew out of the need to assist students attain better intelligibility in English.

English Skills classes at International Pacific College and, I presume, in many other institutions of higher learning comprise a variety of students from different overseas countries, while 'content' classes often have a mixture of native and non-native speakers of English. In these circumstances, mutual intelligibility is of genuine importance on a day-today basis and should be an area of focus for both English Skills teachers and ESL students. Beyond the classroom, intelligible English increases student confidence and assists them with seeking jobs internationally. Given these practical realities, the question arises as to how to achieve intelligibility in EIL speakers.

The teaching of pronunciation in ESOL classes has not always been as successful as other aspects of English teaching, arguably because pronunciation has been traditionally considered a separate skill and has not been well integrated into language courses. If, however, there are ways to address pronunciation in situations that are both relevant and interesting to the 
students, then, presumably, better results can be achieved. This would require pronunciation to be integrated into the context of a paper's text materials and objectives.

International Pacific College is exactly what its name says. Students arrive from all over the world, including Russia, Peru, and Brazil, but the majority of students come from Southeast Asia and the Pacific Rim. It seems unlikely that there could be a better place to observe how exposure to different accents helps students recognise the importance of mutual intelligibility in communication and develop a personal commitment to it. My approach to dealing with pronunciation works best in multinational groups where students must attune their ears to a variety of accents coming from various parts of the world. This eliminates the chance of continuous exposure to the same L1 accent.

\section{Steps to building pronunciation awareness}

English Skills papers run on a tight schedule. Addressing pronunciation within an intense programme of developing other skills, such as academic and general vocabulary, reading, note-taking, essay writing, etc., is an onerous but essential job. It is the teacher's role to initiate the process, encouraging students to continue from there. There is no single way to do this and I would hope that any teacher who values pronunciation would find a way that works for them and their students. However, any transition to intelligibility must confront the important issue of raising students' awareness of their own problems.

In traditional pronunciation teaching, students are asked to repeat words after the speaker. Often, students tend to think that such class drills are sufficient. If this were the case, mastering English overseas would be a realistic option. Instead, many learners come with deeply-entrenched, fossilized pronunciation errors in English which are the result of using their mother-tongue articulation as a basis for speaking English. While class drills allow them

to utter (in the most basic sense of the word) English words and sentences relatively easily, real-life speech often remains a stream of incomprehensible English. Students are missing the point when they try to speak English without realising that, in addition to learning a new set of vocabulary and grammar, they have to abandon their mother-tongue articulation base. Instead, they must consciously re-train their speech organs to produce English sounds and sound groups. 
It follows that students who were unable to master pronunciation in their schools at home must now continually exercise conscious control over the way they create sounds in English, because 'skilled behaviours begin as controlled processes and gradually become automatic through practice'. (Schmidt, 1990, p.136) What needs to be done is to:

- adapt one's organs of speech to a series of new positions in the mouth,

- decondition students from using native language habits while simultaneously reconditioning them to those of the language being learnt, where the latter differs from the former (Brown, 1991, p.2). Thus a long-term, concentrated effort, with a correct perception of the target sounds, is essential to make any progress.

\section{Step 1}

In their ongoing efforts to exhibit signs of 'empowerment' and assume control of their articulation, students need know which specific pronunciation errors they should address in their out-of-class pronunciation training. To this end, the teacher outlines a set of measures to raise the awareness of students and encourage them to understand their own strengths and weaknesses. Prior to doing this, I ask students to answer ten questions. The questions are intended to help students reflect on their pronunciation-asking how they perceive their pronunciation problems and how those problems have affected their attitudes, behaviour, and social life. The questionnaire also asks what their pronunciation goals are and specifically how they deal with their pronunciation problems. Motivated by personal interest, I included a question about which pronunciation instruction models they have been exposed to so far.

Two groups I taught this year were truly diverse. Each group had students from 6 different countries and L1 backgrounds. Despite this diversity, the initial questionnaire, mentioned above, revealed that their pronunciation instruction had been surprisingly similar. Much of it had largely been confined to pronouncing separate sounds, words, and contrasting phonemic pairs, which can be useful in the early stages of language learning but which does not give a real picture of connected English speech. Occasionally, the same students had also imitated sentences and tried singing English songs. I also learned that 14 students out of 27 (52\%) thought it was important to acquire a native English accent. This was a real insight into the naivety of their understanding of the complexity of the pronunciation processes, although not as extreme as the $80 \%$ of the year before. 
Paradoxically, 24 out of 27 (88.8\%) wrote that people could not understand them easily when they spoke. $25(92.6 \%)$ responded that they were not satisfied with their pronunciation. Typically, in response to whether they knew what their own pronunciation problems were,

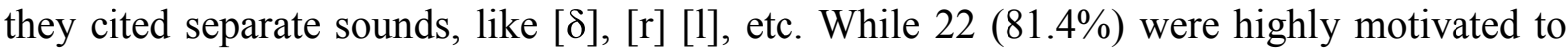
improve their pronunciation, a significant remainder were not prepared to invest any extra effort and were content to stay as they were. Those were students with a reasonable articulation base acquired in private schools in Britain and the US prior to embarking on their higher education in New Zealand.

\section{Step 2}

It was obvious to me that the students lacked general understanding of the phonetics of connected, discourse-level speech, namely rhythm, word stress, sentence stress, intonation, and their communicative value. The value of suprasegmentals as factors contributing to intelligibility has become widely recognised (Brazil et al., 1980; Wong, 1987; Gilbert, 1993; Celce-Murcia, Brinton, \& Goodwin, 1996; Grant, 2001; Miller, 2000; Derwing \& Rossiter, 2003). Brown, for example, writes: "Most modern writers on pronunciation teaching emphasise that it is the supresegmental features which contribute most to a speaker's lack of intelligibility, or foreign accent." (Brown, 1991, p. 4). Other scholars, however, call for further research (Jenkins, 2000, 2007; Levis, 1999, 2005). Although there are different points of view on the seminal importance of different constituents of pronunciation on intelligibility, teaching and learning must continue parallel to ongoing research, the results of which might shift our priorities in the long run.

Students unanimously accepted the idea of five essential components of connected speech, which grew out of David Brazil's theory of discourse intonation (Brazil et al., 1980) and my own English language teaching experience. However, I had to significantly simplify my explanation of these for the purpose of intense, but limited, classroom instruction. The five components of connected speech are:

1. sense groups, BE (Underhill); thought groups, AE (Rogerson \& Gilbert); tone groups, BE (Brazil),

2. notional (stressed) words versus form (unstressed) words in a sense group,

3. reduction of unstressed syllables,

4. time-based succession of stressed/unstressed syllables, and 
5. voice modulation, rise/fall within a sense group and intonation at the end of the statement/question.

To this list I added the important distinction of long versus short vowels. Remaining errors were treated on an individual basis.

A 5-point ESL pronunciation instruction, based on speech flow, was demonstrated with the help of a short transcript of a news item projected onto the board.

Europe's revolution/ twenty years on.//

The year 1989/ reshaped the world.// Its new stories/ - from Tiananmen Square/ to the fall of the Berlin Wall/ - are now historical landmarks.// BBC Diplomatic Editor/ Brian Hanrahan/ watched many of the events/ at first hand,/ and has been retracing his steps/ this year/ to talk to those involved/ and consider the long-term implications.//

Simplified notation for sense groups, stresses, pauses, and intonation was used. The class then listened to three minutes of recorded radio news. After this, I handed out a transcript of the entire recording. Students listened again and marked it, using the same easy notation. Finally, they compared their notes and attempted to practise pronunciation using the notated text.

A significant quantity of information, practise, and analysis was compressed into a short teaching time, but with satisfying results. Through inconsistencies in notation and difficulties in understanding each other, students gained insights into why native speakers find it so hard to follow their English.

However, simple awareness is a passive state. Making the transition to genuine competence, with a command of rhythm and intonation patterns, requires extensive independent drills. At some point during most classes, I repeated that the more they accepted personal responsibility for their pronunciation, the faster it would improve. I encouraged each student to focus on connected, discourse-level speech and think about their individual pronunciation problems at the same time. 


\section{Step 3}

Students were asked to choose an interesting international news item from a written source, notate it according to the rules outlined in my initial presentation, and practise reading it at home. Then, in class, they read it to a partner. The partner commented on the clarity of reading and gave suggestions for improvement. In doing so, intelligibility was negotiated.

\section{Step 4}

Since imitation of L1 speakers was seen as a means of improving pronunciation, I advised students to practise tracking (see Action, 1984; Rosse, 1999). Tracking is simple and readily accessible, thanks to the technology around us. Students select and imitate a sample of an L1 speaker's recorded speech, sentence by sentence, in their own time. Shadowing is another way of imitating and recording one's speech following an existing pattern of one's own choice. Shadowing generally involves the stages described above, i.e. listening to authentic English speech and notating sense groups, stress patterns, intonation. Its point of difference is reading the source text simultaneously with the model speaker, trying to get one's own pronunciation as close to the model as possible.

\section{Step 5}

These initial steps of building pronunciation self-awareness were followed by a reality check (shock therapy for some). To start with, students took turns, one per class, to produce a threeminute recording of their speech. The content was meant to be of genuine interest to the class and could relate to current politics, economics, environment or culture. The recording would then be played in class for the benefit of listening and notes-taking exercise. As study groups are small it took only two weeks to get the whole group through this exercise that served as a diagnostic test for future reference. It took 10-15 minutes of a class time as listening was followed by the discussion of the featured events and the assessment of presenter's pronunciation and choice of items, including news coming from their own home countries. This addressed students' emotional and intellectual involvement, as well, which is essential for effective learning (Harmer, 2006).

The presentation was considered successful if the class understood and found it interesting. In order to be understood presenters had to rehearse repeatedly. Their commitment to out-ofclass practice clearly demonstrated their motivation levels to improve their pronunciation and, in addition, saved class time. 
Another benefit was that students retained control over the process. Initially, they were primarily focused on the selection of news items with the goal of motivating their peers to listen, make notes, and ask questions. Selecting interesting extracts required surveying a significant amount of authentic news texts, boosting both students' reading skills and interest in the news. Only then their attention moved to pronunciation training.

Following the trial, each student received a personal chart of the main pronunciation errors to focus on. From this point, they started making a conscious effort to improve, first by highlighting their personal 'problems' in whatever text they were practising independently, and then by trying to make the correct sounds without reference to the printed text. I urged students to use the five-point pronunciation instruction to assist them with text notation to improve prosody.

Step 6

The test recording was followed by a second, and final, recording, which was assessed. Thus, each student presented self-recorded news twice a term, first as a trial and then as part of an assessment, with a gap of a few weeks to allow for independent drills. In a relatively similar experiment, but carried out in a homogeneous L1 group and with a single selected text, Robin Walker remarks on the positive effect of 'the amount of rehearsal prior to making the recording, and the number of attempts at recording before feeling satisfied'. She then rightly asserts: 'This repetition parallels the intensive practice that teacher-led drills provide in the classroom and is beneficial when trying to establish automatic pronunciation habits' (Walker, 2005, p.556).

During both the trial and final presentations, all class members listened to the same new, content-dense text. Their ability to comprehend it largely depended on the intelligibility of the reader's pronunciation. Pronunciation was ultimately unintelligible if all five components (as listed earlier) were deemed unclear. Because understanding of vocabulary contributes to comprehensibility, students were asked to project (OHP) or write (whiteboard) new words and word groups, and their definitions, prior to playing the recorded text.

Students' overall performance was assessed with the help of a rubric evaluating both content and form. A nil result was hard to generate, because points were given for effort in finding 
and choosing current, relevant, and interesting national and international news items. Final recordings overwhelmingly revealed that significant improvement was possible with persistent, short-term commitment. Hopefully, the commitment becomes long-term, which will happen if students keep paying attention to, and modifying, pronunciation while they work on other language skills.

\section{Step 7}

At the conclusion of the course, the students completed another survey reflecting on their learning and achievement. In it, they commented on improvements in their intelligibility and outlined a vision for further progress. Here are some comments from the questionnaire:

- Because I want everyone to understand my news recording I try to pronounce the text carefully. It made me practice many times.

- I never recorded my voice in English. When I did I realised that my pronunciation is difficult to understand.

- By listening to my own recording I discovered my pronunciation problems such as [w] and speaking with my mouth closed.

- In everyday life we speak English but we do not use academic words. The SRN was a good opportunity to say unfamiliar words and I think it helped my pronunciation.

- I learned how to link words when pronouncing them and where I should stop for a pause. It is important to connect words.

Step 8

Ongoing encouragement was needed to sustain students' motivation after the course was completed. "Dramatic changes in students' speech in 3 to 6 months are rare, but changes in their perception of speech phenomena in their own speech and that of a native speaker can be significant." (Wong, 1987, p. 8). In my students' case, the time frame was even tighter, and the most important outcome was that they became aware of how to control and modify their pronunciation. With inner discipline, they were able to build on their success.

\section{Final observations}

This project targeted pronunciation awareness and improvement, and prompted one way of addressing it in the classroom. The project's components were deeply imbedded into other academic skills, such as scanning and reading the news, editing it to suit the recording format, 
and learning the meanings and pronunciation of new words from one's own work and from the work of others. More often than not, thanks to the prescribed thematic field, the words happened to be from the Academic Word List (Coxhead, 2000), thus developing the students' vocabularies. Last but not least, the class was actively involved in note-taking, asking clarification questions and discussing the outcomes of each recording. Students did substantial out-of-class preparation, which gave them clear responsibility for the success of their learning and saved much class time.

Pronunciation is a complex phenomenon. It involves both physical and mental activity. Improvement is possible for as long as the individual remains aware of it and interested. It is not only aptitude which allows students to modify their pronunciation; attitude is equally important.

Exposure to the variety of accents within my group, as well as to other varieties of English on campus and in the media, gave students skill in decoding a range of types of speech. Ongoing examination of their own speech took place simultaneously. As students' intelligibility improved they grew more confident of their language performance and were able to witness the positive result of their effort. The time invested in pronunciation self-training paid off and translated into improved overall comprehensibility which facilitated oral communication.

My experiment grew out of an intrinsic need for students to be intelligible in different communicative situations, whether NNS to NS, or NNS to NNS. My goal was to stimulate students' autonomous learning. Their learning was initiated by a teacher but subsequently monitored by themselves. In a classroom environment, the process was directed at transforming different national varieties of English into a mutually-intelligible, international variety. 


\section{References}

Action, W. (1984). Changing fossilized pronunciation. TESOL Quarterly, 18(2), 71-85.

Brazil, D., Coulthard, M., \& Johns, C. (1980). Discourse intonation and language teaching. London: Longman Brown, A. (1991). Pronunciation models. Singapore University Press.

Celce-Murcia, M., Brinton, D. M., \& Goodwin, J. M. (1996). Teaching pronunciation: A reference for teachers of English to speakers of other languages. Cambridge, England: Cambridge University Press.

Coxhead, A. (2000) A new academic word list. TESOL Quarterly, 34, 213-238

Cruz, N. C. (2007). Terminologies and definitions in the use of intelligibility: state-of-the-art. Rev. Brasileira de Linguistica Aplicada, 7(1), 149-159

Dalton, C. \& Seidlhofer, B. (1994). Pronunciation. Oxford University Press.

Dauer, R. (2005) The Lingua Franca Core: a new model for pronunciation instruction. TESOL Quarterly, 39(3), 543-550.

Derwing, T. M. \& Munro, M. J. (2005) Second language accent and pronunciation teaching: a research-based approach. TESOL Quarterly, 39(3), 379-398.

Derwing, T. M., \& Rossiter, M. J. (2003). The effects of pronunciation instruction on the accuracy, fluency, and complexity of L2 accented speech. Applied Language Learning, 13, 1-17.

Dickerson, W., 1994. Empowering students with predictive skills. In: J. Morley, (Ed.), Pronunciation Pedagogy and Theory: New Views, New Perspectives. 36-48, TESOL, Alexandria, VA,

Gilbert, J. B. (1993). Clear speech: Pronunciation and listening comprehension in North American English. Student's book ( $2^{\text {nd }}$ ed.). New York: Cambridge University Press.

Gimson, A. (1989). An introduction to the pronunciation of English. ( $4^{\text {th }}$ ed.). London: Edward Arnold.

Grant, L. (2001). Well said: Pronunciation for clear communication ( $2^{\text {nd }}$ ed.). Boston: Heinle \& Heinle.

Jenkins, J. (2000). The Phonology of English as an International Language, OUP

Harmer, J. (2001). The practice of English language teaching. Longman.

Harmer, J. (2006). Engaging students as learners. English Teaching Professional, 42, 4-6.

Kelly, I. G. (1969) 25 centuries of language teaching. Rowley, MA: Newbury House

Kenworthy, J. (1987). Teaching English pronunciation. London: Longman.

Levis, J. (1999). The intonation and meaning of normal yes-no questions. World Englishes, 18(3), 373-380.

Levis, J. (2005) Changing contexts and shifting paradigms in pronunciation teaching. TESOL Quarterly 39(3), 369-377.

Levis, J. (2007) Computer technology in teaching and researching pronunciation. Annual Review of Applied Linguistics, 27, 184-202.

Miller, S. F. (2000). Targeting pronunciation: The intonation, sounds, \& rhythm of American English. Boston: Houghton Mifflin.

Morley, J. (1994) Pronunciation Pedagogy and Theory: New Views. New Perspectives. TESOL, Alexandria, VA.

Morley, J. (1998) Tripping on the tongue: Putting serious speech/pronunciation instruction back in TESOL equation. ESL Magazine, January/February, 20-23.

Murphy, J. \& Kandil, M. (2004). Word-level stress patterns in the academic word list. System 32, 61-74

Pennington, M. C. (1997). Phonology in English Language Teaching. Longman

Pickering, L. (2006). Current research on intelligibility in English as a Lingua Franca. Annual Review of Applied Linguistics. 26, 219-233. USA: Cambridge University Press

Rogerson, P. \& Gilbert, J., (1990). Speaking Clearly, Cambridge: CUP

Underhill, A. (1994). Sound Foundations. Macmillan Heinemann.

Rosse, M (1999) Tracking - a method for teaching prosody to ESL learners. Prospect, 14, 53-61

Schmidt, R. (1990) The Role of consciousness in second language learning. Applied Linguistics, 11, 129-58.

Wajnryb, R. (2004) Review of Clearly Speaking. EA Journal, 22(1), 90-92.

Walker, R. (2005) Using student-produced recordings with monolingual groups to provide effective, individualized pronunciation practice. TESOL QUARTERLY 39(3), 550-558

Wong, R. (1987). Teaching pronunciation. Focus on English rhythm and intonation. Englewood Cliffs, NJ: Prentice Hall Regents. 